\title{
SPINA BIFIDA AND HYDROCEPHALUS IN CHILDREN: ROLE OF A PAEDIATRIC SURGEON
}

\author{
MTH SIDDIQUI ${ }^{1}$, S ALAM $^{2}$, ZAHMED $^{3}$
}

\begin{abstract}
:
Spina bifida and Hydrocephalus is one of the most common malformations in Paediatric Surgery. Though the two diseases has their own way of presentation but Spina bifida is accompanied by hydrocephalus in 80 to $90 \%$ of cases and treatment protocol is interrelated. As a general paediatric surgeon of the third world country we are facing the challenging job in our day to day practice. The etiology, pathophysiology, diagnosis, treatment and prognosis is not well understood and gratifying. We don't have so much interest on the most vital but neglected birth defect. My aim of discussing this two entity at a time to show light on this malformation and make all paediatric surgeon a bit conscious about the disease process and treatment modalities. So that only referring the patient to a tertiary hospital is not the job of a paediatric surgeon rather we must come forward to prevent and treat this major morbid diseases with ourselves. As a paediatric surgeon our role is not to become a good general paediatric surgeon, also acquire proficiency on other speciality like urology, neurosurgery, orthopaedics, reconstructive \& oncology.
\end{abstract}

\section{Introduction:}

Mylomeningocele (MMC) is the most common congenital malformation of the central nervous system and affects approximately 20 per 100,000 live births

1. Prof. Dr. Md. Tosadeque Hossain Siddiqui, Department of Paediatric Surgery, Bangabandhu Sheikh Mujib Medical University, Dhaka.

2. Dr. Shoheli Alam, Assistant Professor, Department of Paediatric Surgery, Bangabandhu Sheikh Mujib Medical University, Dhaka

3. Dr. Zeba Ahmed, Jr. Consultant, Department of Gynae and Obs., Shahid Suhrawardi Medical College, Dhaka

Correspondence: Prof. Md. Tosaddeque Hossain Siddiqui, Department of Paediatric Surgery, Bangabandhu Sheikh Mujib Medical University, Shahbagh, Dhaka. Email: t_siddiqui_2000 @yahoo.com annually in the United States ${ }^{1}$. MMC is accompanied by hydrocephalus in 80 to $90 \%$ of cases ${ }^{2}$. Overt hydrocephalus is found at birth in only 5 to $15 \%$ of patients with $\mathrm{MMC}{ }^{(3)}$. And an additional 65 to $75 \%$ of patients develop symptomatic hydrocephalus within a few days of birth, usually following repair of the MMC. Hydrocephalus in MMC patients is considered to be of an obstructive type, most commonly secondary to posterior fossa crowding resulting from the associated Chiari type II malformation ${ }^{4}$. In the ara before modern surgery, the vast majority of MMC patients died in infancy from meningitis or uncontrolled hydrocephalus. With the advent of modern neurosurgical techniques, the spinal defect could be repaired, but without an effective treatment for the developing hydrocephalus, mortality rates remained high. In the late 1950s, the advent of the cerebrospinal fluid (CSF) shunt offered an effective method of treating hydrocephalus in MMC patients. Management strategies of hydrocephalus in patients with MMC evolved gradually, and by the 1970s, the goal of long-term survival had been reached. Focus has since turned to decreasing the significant morbidity associated with treating these patients. The past thirty years have seen great advances in shunt systems, imaging technologies, and surgical techniques resulting in safer and more effective treatments. Other advances, such as endoscopic third ventriculostomy (ETV) have been highly controversial in treating MMC patients ${ }^{5}$.

\section{About Spina Bifida:}

The term spina bifida refers to any defect, ranging term anencephalus to spina bifida oculta due to 
abnormal closure and development of the neural tube and neighbouring tissue along the posterior midline of the body. It is one of the commonest malformation of the central nervous system. Though the incidence is now on declining in Western World ${ }^{6,7}$. The precise reason for this change is unclear. The decline rate can be particularly explained by increased widespread prenatal diagnostic techniques declining birth rate, improve standard of living with dietary improvement fortified with folic acid.

The association of spina bifida with hydrocephalus was recognized by Morgani in 1961. He also described anencephaly and spina bifida as expression of the same pathological process and

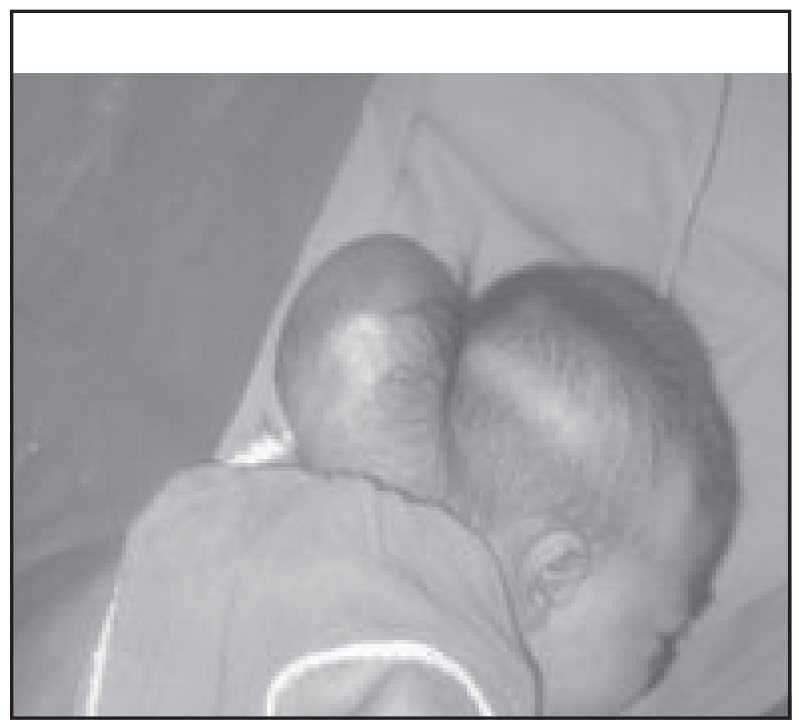

Fig.-1: Cervical Meningocele



Fig.-2: Lipomyelomeningocele attributed bladder, rectal and limb abnormalities to the neural damage in the defective spinal $\operatorname{cord}^{8}$.

Although, the hydrocephalus is one of the association of spina bifida it may present alone and the treatment modality and prognostic criteria is different if it present with spina bifida.

There are four prognostic criteria associated with poor prognosis:

a. Gross hydrocephalus

b. Severe paraplegia

c. Kyphosis

d. Gross congenital abnormalities or major birth injury

It is suggested that a body with one or more. Adverse criteria should be selected for no treatment as very few patients with such adverse criteria would live and those who live would be severely mentally and physically handicapped.

The management of spina bifida and hydrocephalus with other birth defect stirred great deal of medical, ethical and legal controversy over the last 3 decades. Management of this infants should be individualize and changed wherever necessary with a team approach involving Paediatric Surgeon, Neonatologist, Neurologist, Paediatric Urologist, Paediatric Neurosurgeon, Radiologist, Physiotherapist, Social worker, Psychologist, Nursing staff and most of all, family and society so that the best interest of the patient is being maintained 9,10 .

Neurulation one of the earliest and most crucial events in human development, generates the neural tube (NT). The NT forms during primary and secondary neurulation. The primary neurulation encompassed the formation of neural plate (NP) and the subsequent morphogenetic movement that transform into a NT. Secondary neurulation involves the formation of an epithelial cord (medulla cord) and its subsequent cavitation to form a NT.

\section{Types:}

Primary neural tube defect:

These constitute approximately $95 \%$ of all neural tube defect. They are due to primary failure of closure of the neural tube or probably disruption of an already closed neural tube between 18-28 days of gestation. It cause two anatomical abnormalities: (1) Exposed (open or operta) caudally \& Rostrally. (2) The Arnold Chiari II malformation (malformation of pons and medulla, downward displacement of cerebellum and fourth ventricle with aquductal stenosis and hydrocephalus ${ }^{11}$. The most severe are 
craniorachischisis and anencephaly which is incompetable with life ${ }^{12}$.

a. Meningomyelocele - This is the most common neural tube defect. It involves a saccular out pouching of neural elements (neural placode) typically through a defect in the bone and the soft tissue of the posterior thoracic, lumber or sacral region. Hydrocephalus occurs in $84 \%$ of the children. Arnold Chiary II malformation occur in almost $90 \%{ }^{13}$.

b. Encephalocele - Occipital cervical and frontal. The defect is an outpouching of dura with or without brain.

c. Anencephally - Most severe form of this defect, the cranial vault and posterior occipital bone are defective, and derivative of the neural tube and exposed. The life is impossible with this defect.

Secondary neural tube defect:

About $5 \%$ of all neural tube defect are secondary neural tube defect, resulting from abnormal development of the caudal cell mass or following primary neural tube closure. This heterogeneous lesion rarely associated with other co-morbid lesion like hydrocephalus or Arnold Chiari and skin is intact over the defect ${ }^{14}$.

a. Meningocele: This is an out pouching skin and dura without obvious involvement of neural elements.

b. Lipomeningocele: Lepomatous mass usually is the lumber or sacral region. Occasionally off the midline, typically covered with full thickness skin. Adipose tissue frequently extends through the defect into the spinal canal and dura.

c. Sacral agenesis/ Dysgenesis diastematomyelia, Myelocystocele: Where there is varying degree of bony involvement. They may present in latter life with tethering of the cord.

\section{Epidemiology:}

In USA the overall frequency of NTD is 1 in 2000 live birth and is decreasing. In parts of Ireland and Walse it is increasing 4.2-12.5 per 1000. Low social group have a higher incidence of defect. The exact cause of failure of neural tube is unknown over $95 \%$ has got no known family history ${ }^{15}$. Primary neural tube defects carry an increase empiric recurrence risk of 1 in 33 for couples with one affected pregnancy and 1 in 10 for those of two affected pregnancy. Affected individual have a 1 in 25 risk of having one offspring with a primary NTD. Sisters of women with an affected child have a 1 in 100 risk. Sister of a man with an affected child have a 1 in 300 risk. Brother of parent an affected child have a 1 in 500 risk. Secondary NTD are generally sporadic and carry no increase recurrence risk ${ }^{16}$.

\section{Etiology:}

The primary and secondary NTD is heterogenous. They include some known and some suspected factors. Case of such defect is probably multifactorial with both genetic and environmental factors known factors:

a. Maternal alcohol, cigarette smoking

b. Aminonopterion or Thalodemide

c. Maternal diabetics, Obesity

d. Prenatal X-ray irradiation

e. Amniotic band disruption

\section{Prevention:}

Mother of spinal bifida patients were found to have and increase incidence of Folate metabolism abnormalities. Recently, The Medical research council conducted a randomized double blind prevention trial in several countries to determine whether the supplementation of with folic acid or mixture of seven other vitamins ( $A, D, B, B, B, C$ \& nicotinamide) around the time of conception could reduce NTD ${ }^{17}$.

The centers for disease control of US public health service recommends that women of child bearing age who are capable to become pregnant should consume $0.4 \mathrm{mg}$ of folic acid per day to reduce their risk of having a fetus affected with spina bifida or other neural tube defect $18,19,20$.

\section{Diagnosis:}

Allows both improved obstetric case and conversely, termination of and severely affected fetus if desired.

\section{Prenatal:}

Combination of maternal serum á fetoprotein (AFP) and prenatal ultrasonography and accetylcholinesterase determination on amniotic fluid were indicated greatly improve the diagnostic capability.

1. Maternal AFP in second trimester (16-18 weeks) can diagnosed $90 \%$ of fetus with encephalocele and $80 \%$ of those with open myelomeningocele

2. Chronic villous sampling

3. Amniocentesis 


\section{Postnatal:}

Except some secondary NTD, The most neural tube defect specially Myelomeningocele are immediately obvious at birth. Some sacral region swelling may be confused with saccrococcygeal teratoma.

\section{Diagnostic tools:}

1. Radiograph - chest, spine hip

2. USG - Brain to exclude/ include hydrocephalus

3. $\mathrm{CT} / \mathrm{MRI}$

4. Urine analysis for dribbling of urine

5. IVU/ Urodynamics - in appropriate age

\section{Evaluation and treatment:}

At the time of birth the NTD were present accordingly. In typical Myelomeningocele, a neural placode has a sac like protrusion bathed in CSF. The sac may be intake or leaked. The associated anomalies like hydrocephalus, Arnold Chiari II malformation, syringomyelia, brainstem malformations, agenesis of corpus callosum and polymicrogyria.

Shortly after birth a thorough physical examination is performed that includes measurement of head circumference and assessment of general Vigor (Cry and Suck) and sphincter function, motor function and sensory function and the site, level and size of Myelomeningocele. In addition the neonate should be evaluated for hydrocephalus. Arnold Chiari II malformation, orthopaedic defect such as Club foot and Kyphoscoleosis.

Before repair the neonate should be in prone position with a sterile saline soaked gauze on the defect to prevent dessication of the exposed neural tissue. Administration of intravenous antibiotic to reduce the risk of meningitis.

\section{Surgical Treatment:}

The closure of the back lesion within 24 hours will improve neurological status.

The goal of the surgery: to closure the neural placode into a neural tube to establish a micro environment conducive to neural function ${ }^{21}$

\section{Closure involves.}

1. Separation of neural placode from the intermediate zone and reconstruction of the placode into a tube with preservation of all neural tissue.
2. Separation of dura from the epidural space at the lateral margin of defect and closure in a water tight, but patulous fashion around the newly created NT.

3. Surgical correction of any significant kyphotic deformity.

4. Mobilization end fascia

5. Tension-free closure of the skin in the midline, which often requires mobilization of the skin and subcutaneous tissue from the underlying fascia rostrally, caudally and bilaterally.

\section{Common complication:}

- CSF leak

- Wound-healing problem

- Tethered SC

\section{Prognosis:}

- Mostly survive for many years due to early detection and various intervention

- Overall one year survival over $96 \%$.

- 10 years survival is $90 \%$

- Mostly death occur due to SIDS

\section{Motor \& Intellectual outcome:}

Motor: This depends on the level of paralysis motivation and surgical intervention. There is delay in motor prognosis in most children with NTD but appropriate bracing, physical therapy, intervention treatment of Kyphosis and scoliosis can mitigate this. Other factor like, obesity, decubitus ulcer, tethering of cord can further delay in motor progress.

\section{Intellectual outcome:}

Three identifiable sub group at risk for mental retardation:

(a) with severe hydrocephalus at birth (b) infection in CNS at birth and there (c) whose intracranial hypertension in not properly controlled.

\section{Morbidity:}

It is a great challenge to overcome morbidity of the child. If government is not support it is great social burden.

\section{Following are the recommendation:}

Preconceptional folic acid 400/gm/day.

Who are pregnant $1 \mathrm{mg} /$ day.

Who previously gave birth NTD 4 mg/day. 
Recently fortification food like, bread cereals, flour with addition of folic acid in Canada it is mandatory has shown the incidence reduce $46 \%$.

However scientist in 2011 reported that there genetic mutant which responded adversely to folic acid supplementation.

\section{About Hydrocephalus}

Hydrocephalus is defined as a pathological condition in which ventricular enlargement is associated with elevated intracranial pressure that occurs when the amount of cerebrospinal fluid (CSF) produced exceeds the amount absorbed. This is most common condition that paediatric neurosurgeons treat. The incidence of congenital hydrocephalus is approximately $0.9-1.8$ per 1000 birth. It comprise



Fig.-3: Hydrocephalus with setting sign

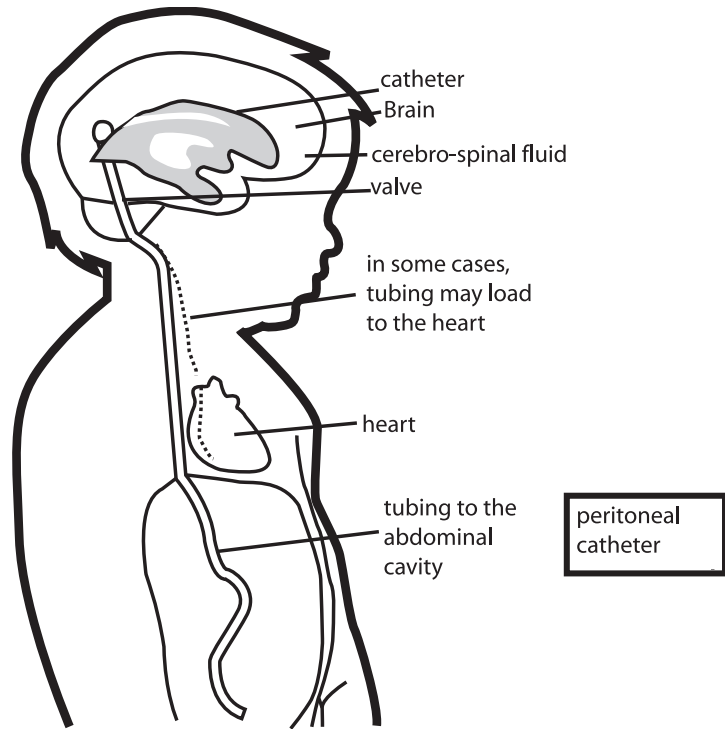

Fig.-IV: VP Shunt.
$30 \%$ of all congenital malformation of CNS and often associated with NTD $70 \% 22$.

\section{Physiology of CSF Formation:}

The amount of CSF is around $150 \mathrm{ml}$ in adult and amount of CSF produced is $20 \mathrm{ml} / \mathrm{hr}$. irrespective of age i.e $500 \mathrm{ml} / \mathrm{day}$. Source of CSF $65-80 \%$ from choroid plexus, $15-30 \%$ for ependymal surface of ventricles and arachnoid membrane. Small amount produce by brain itself through the pervascular space surrounding the blood vessels entering the brain. Rate of production $0.02 \mathrm{ml} / \mathrm{min}$ in neonate and total ventricular CSF volume varies between $5-15 \mathrm{ml}$.

\section{CSF flow:}

CSF formed by choroid plexus of the lateral, third and fourth ventricles by an active transparent process. It comes from lateral to third ventricle then along the aqueduct of sylvius into the fourth ventricles then passes out of fourth ventricles through two lateral foramina of luschka and magendie into the cisterna megna. This is continuous with subarachnoid space that surrounds the entire brain and spinal cord. From the subarachnoid space the CSF is absorbed into the large sagittal venous sinus and other sinuses by multiple arachnoid villi projecting into the sinuses.

The rate of CSF absorption is pressure dependent over a wide physiological range. CSF formation is pressure independent but absorption increase linearly after $6.8 \mathrm{~cm} \mathrm{H}_{2} \mathrm{O}$ pressure. The formation and absorption became equal at $11.2 \mathrm{~cm} \mathrm{H}_{2} \mathrm{O}$ pressure.

\section{Pathophysiology:}

Ventricular enlargement is caused by undamped pulse wave generated by the choroid plexus. The subarachnoid channel are the first CSF compartment of dilate and reduce CSF pressure. Latter with progressive dilatation of subarachnoid channels increase in CSF pressure is transmitted to the ventricular system resulting in ventriculomegaly.

The effect of increased intracranial pressure on brain as follows-

1. Atrophy of white matter

2. Stretching and denuding of ependymal epithelium with formation of ventricular diverticulum

3. Spongy oedema of brain parenchyma surrounding the ventricle.

4. Fenestration of septum pellucidum

5. Thinning and elongation of the intrahemispheric commisure

6. Fibrosis of choroid plexus 


\section{Etiology and classification of hydrocephalus:}

Genetic Factors: The most common inherited form of hydrocephalus, X-linked hydrocephalus is characterized by mental retardation, adducted thumbs and spastic paraplegia.

\section{Environmental:}

The incidence of congenital hydrocephalus was more in mother who took oral contraceptives in first trimester and in family with parental consanguinity.

\section{Classification:}

1. Non communicating:

a. Congenital: Stenosis of aqueduct sylvius, Dandy-Walker malformation, suprasellar arachnoid cysts

b. Acquired : Tumours, cyst, Haemorrhage

2. Communicating

a. Increased production: choroid plexus papilloma

b. Decreased absorption: Haemorrhage, infection, venous hypertension, sinus thrombosis

\section{Other hydrocephalus}

Hydrocephalus of excavio - due to cerebral atrophy

Low pressure hydrocephalus

Arrested hydrocephalus

\section{Clinical Presentation:}

There may be positive history of congenital hydrocephalus in the family or history of fever in first trimester or the child has other associated congenital anomalies like Myelomeningocele or Spina bifida.

The sign and symptom related to hydrocephalus depends on the age of the patient, causative factor, associated anomalies and severity and progression of the disease. The child may have a big head with no symptom or a normal looking head with severe headache, seizure, convulsion etc. Presenting feature are divided into two group: newborn or infant, or acute and chronic onset.

\section{Seven cardinal signs}

1. gradual enlargement of head

2. wide and bulged ant fontalle

3. prominent engorged skull vein

4. setting sun sign
5. Mc weans sign

6. frontal bossing

7. microfacia apparent

\section{Head Enlargement:}

Head circumference above $97^{\text {th }}$ percentile of gestational age and progressive increase on weekly measurement is diagnostic of hydrocephalus.

1. Normal head circumference at birth is $33-35 \mathrm{~cm}$. In normal infant approximate $2 \mathrm{~cm}$ per month for $1^{\text {st }} 3$ month. $1.5 \mathrm{~cm}$ for next 3 month. From 6-9 month by $1.5 \mathrm{~cm}$ every 2 months and $9-12$ approximately $1 \mathrm{~cm}$ increase in every 3 months.

2. Sutural separation -Anterior fontanelle is wide open, it is either full or bulged.

\section{Differential diagnosis of big head:}

1. Subdural fluid

a. Hygroma

b. Haematoma

c. Effusion

2. Brain oedema

3. Familial or constitional macrocrania

4. Gigantism

5. Achondroplastic dwarfism

6. Leukodystrophy

7. Amino acidurea

8. Thallasemia, craneo skeletal dysplasia

9. Hydroencephaly

10. Craniosynotosis

\section{Investigation:}

Antinatally by ultrasound is extremely useful as a non invasive technique and will usually indicate the anatomical arrangement and cause of hydrocephalus.

In newborn by ant. fontanelle measurement of ventricular dilatation and cortical thickness is possible.

CT scan is used while anterior fontanelle is closed either with due to age or cranyosynostotic hydrocephalus. It is particularly useful while any tumour or sol is suspected.

MRI provide ever more useful and certainly has shown up posterior fossa tumour not detected by CT. MRI can showing such causative processes as aquedectal stenosis and Chiari malformation with remarkable clarity ${ }^{23}$

CSF analysis is required when infective hydrocephalus or post shunt infection is suspected. 
Invasive pressure measurement are less after justified with modern methods of imaging and fontometry is unreliable ${ }^{(24,25)}$. Transcranial Doppler ultrasound studies of blood flow and tympanic membrane dysplant may prove to be useful in management of hydrocephalus ${ }^{26}$.

Ventriculography - to differentiating communicating and nocommunicating types of hydrocephalus.

\section{Treatment:}

Modalities of treatment

(a) Fetal surgery.

Some scientist attempt to intervention of hydrocephalus and spina bifida in intrauterine life. But so far the result is not so good and this method of management is not currently recommended ${ }^{27}$.

(b) Postnatal therapy:

Not all cases of hydrocephalus require treatment. Since some may arrest. However they need long term follow up because some may have normal pressure hydrocephalus with progressive neurological impairment and need surgical management.

\section{Pharmacological management:}

It is beneficial for slowly progressive hydrocephalus. Medical treatments advocated as the initial line of management for all case of hydrocephalus due to growing reservation against shunt surgery. Shunt insertion represent a life time commitment to an imperfect device that may require frequent revisions. Condition associated with treatable etiology fairly with medical treatment. Hydrocephalus associated with hyper vitaminosis $A$ is very effectively treated by medical management. Pharmacological age like acetazolamide $50-100 \mathrm{mg} / \mathrm{kg} / \mathrm{day}$, Glycerol $2 \mathrm{mg} / \mathrm{kg}$ every 6 hours and isosorbide $2-3 \mathrm{gm} / \mathrm{kg}$ used for medical treatment with mixed result.

\section{Options:}

- Choroid plexectomy

- Elimination of obstruction

- $3^{\text {rd }}$ ventriculostomy

- Shunting

\section{Surgery:}

A shunt operation is most commonly performed surgery for hydrocephalus. It is the definitive operation of choice is children of all age.
This shunt comprises:

3. a ventricular catheter,

4. a valve or flashing device beneath the scalp,

5. a long kink resistance tube passing along the chest wall to enter the peritoneal cavity.

Other shunt systems:

a. Ventriculo atrial

b. Ventriculo pleural

c. Lumboperitoneal

d. Ventriculo cisternostomy

e. Most recently - Third ventriculostomy

Indication:

a. Rapidly progressive hydrocephalus

b. Progressive hydrocephalus with spina bifida

c. Symptomatic patient, with normopressure hydrocephalus

d. Failed medical management

e. Hydrocephalus due to excision of MMC

Contraindication:

a. Ventriculitis

b. Acute intraventricular haemorrhage

c. Extreme brain atrophy

d. Ventriculomegaly without raised ICP

e. Asymptomatic non progressive HCP

f. Irrecoverable optic atrophy with gross hydrocephalus.

There are available in 4 design:

1. Holter valve (slit)

2. Hakim (ball and cone)

3. Upadhyay (Diaphragm), Chhabra ceredrain, pudenz

4. Miter valve

Variable resistance flow regulated valve:

1. QSV (Orbis-Sigma valve)

2. Delta valve

Shunt insertion:

The choice of shunt depends on the condition of patient and surgeon choice. The equipment used for shunt insertion also varies from surgeon to surgeon but the principles of strict asepsis should be almost same.

Two approach:

1. Parieto-occipital into the frontal horn

2. Anterior approach through the frontal lobe at the area of coronal sulcus. 


\section{Distal catheter:}

Length of distal catheter varies according to the manufacturing company. The Chhabra shunt has 75 $\mathrm{cm}$ of distal catheter length. There is no rigid guide line but some principle of insertion. The length usually 4-6 inches and placed either over right dome of liver or deep in the pelvis.

\section{Shunt Complication:}

Complication related to ventricular end-

1. Shunt infection.

2. Shunt obstruction.

3. Shunt disconnection or fracture.

4. Shunt migration.

5. Overdrainage: slit ventricle syndrome.

6. Subdural/Extradural CSF collection.

7. Craniosynostosis.

8. Seizure.

9. Pneumocephalus.

10. Isolated Ventricle Syndrome.

Complication related to peritoneal end-

1. Inguinal hernia and hydrocele.

2. Ascites.

3. Pseudocyst formation.

4. Intestinal volvulus and obstruction.

5. Bowel perforation, bladder perforation.

6. Peritonitis

\section{Outcome of prognosis:}

Natural history of untreated hydrocephalus is poor, with $50 \%$ dying before 3 years of age, only $20-23 \%$ reaching adult life. Of the survivors only $38 \%$ had normal intellingence ${ }^{28}$. The development of CSF diversion technique has improved the prognosis, may patient having shunted have normal intelligence and participate in all aspects of sound life but cognitive development and life expectancy determined primarily by the underlying condition. Over $50 \%$ of shunted patient gain IQ above $80^{29-31}$.

\section{Advances in shunt design:}

General development in shunt system have been made since their introduction in early 1950's. Recent advances includes (a). programmable valves (b). Antisiphon device and (c). Telemetric pressure sensor. Significant controversy exist over which shunt is best in the treatment of paediatric hydrocephalus and randomized controlled trial have yet to show any difference in shunt failure between various design 30,31 .

\section{Follow up and prognosis:}

Monitoring of hydrocephalus patient is usually related to the etiology and associated condition. Most published give report long term survival $50-90 \%$ is surgically treated patients ${ }^{32,33}$.

Patient with myelomeningocele associated hydrocephalus have a higher monitoring rate as compared to isolated hydrocephalus, vascular shunted patient have higher mortality then peritoneal shunt $19 \%$ vs $11 \%^{34}$.

The IQ of the patient related with the cortical thickness as follows.

a. Patient with cortical thickness $<2 \mathrm{~cm}$ is uneducable

b. The cortical thickness between 2-3 cm develop IQ $<100$.

c. Patient cortical thickness more than $3 \mathrm{~cm}$ have normal IQ.

d. The best result of shunt surgery are obtained in infant below 5 months of age.

- Patient with Myelomeningocele associated hydrocephalus have a better intellectual outcome.

- Only $35 \%$ of patient with hydrocephalus have normal cognitive development.

- The case of children with hydrocephalus required a multimodality approach. Early detection and treatment with regular follow up can ensure a favourable outcome.

\section{Recent advancement:}

a. Newer shunt device (SAPLY SV8) controllable pressure valve.

b. Endoscopic laser ablation of choroid plexus.

c. Gentian violet impregnated shunt to reduce incidence of shunt infections.

d. Endoscopic third ventriculostomy.

\section{Conclusion:}

Spina bifida and hydrocephalus may present at a time or may present differentially. The anomaly occurs at conception. It can be diagnosed at 20 weeks of pregnancy. The Gynae and obs specialist become confused when they find this morbid anomalies at the late half of pregnancy. To terminate or not, a great ethical question. Paediatric surgeon has a definite role to solve this in the context of knowledge 
and practice. Though of apparently a different task but the paediatric surgeon can't avoid it.

\section{References:}

1. Lary JM, Edmonds LD. Prevalence of spina bifida at birth; United State 1983, 1990. MMWR morb mortal wkly Rep. 1996; 45: 15-26

2. Gamache FW Jr. Treatment of hydrocephalus in patient with meningocele or oncephalocele; a recent series. Child Nerv Syst. 1995; 11(8): 487-8.

3. Stein SC, L Schut. Hydroephalus in myelomeningocele. Childs Brain. 1979; 5(4): 413-9.

4. Mc Lone DG, MS Dias. The Chiari II malformation cause and impact.Child nerv syst. 2003; 19 (78): 54-50.

5. Grotenhuis JA, T Beems. Endoscopic third ventriculostomy for hydrocephalus in the child with spinal dysraphism. Minim Invasive Neuro Surg. 1996; 42:161-62.

6. Bell WO, E Arbit RA Fraser. One stage meningocele closure and ventriculoperitoneal shunt placement. Surg Neurol. 1987; 27(3): 233-6.

7. Anonymous, Prevalence of neural tube defect in twenty region of Europe and aspect of prenatal diagnosis 1980-1986, Eurocat working group. J Epidemiol Community Health. 1991; 45(1): 52-8.

8. Yen IH, Khrury MJ, Erickson JD, Janes LM, Waters GD, Berry RJ. The changing epidemiology of neural tube defect. United States, 1968-1989. Am J Dis Child. 1992; 146(8): 57-61.

9. Morgagni JB, Je Sendibus. Et Causis morborun per indagatis, Naples: Typographia Simoniara. 1962; 17(2):123-34

10. Surana RH, Quinn FMJ, Guiney EJ, Fitzgerald RJ. Are the selection criteria still applicable in the management of spina bifida. Evr. J Ped Surg. 1991; 1:35-7.

11. McCarthy GT. Treating Children with spina bifida an individual programme for each child. Br Med J. 1991; 302: 65-6.

12. Dias $M S$ et al. Spinal Dysraphism. In: SL Weinstein(ed), The paediatric spine, Principles and proactive. New York: Raven; 1994.

13. Volp JJ. Human brain development. In: JJ Volpe (ed), Neurology of the newborn. $3^{\text {rd }}$ Ed. Philadelphia: Saunders; 1995; 3.
14. McLaughlin DG et al. Early neural development and the embryogenesis of Dysraphism. In: W Chadduck (ed), Paediatric Neurosurgery. $3^{\text {rd }}$ ed. Philadelphia, Saunders; 1994.

15. Kaplan LC. Evaluation of child with congenital anomalies. In: IL Rubin AG Croker (ed), developmental disabilities, Medical care for children and adult.Philadelphia: Lea and Febiger; 1989.

16. Angerpointner TA, Pockrand L, Schrocrk. Course of pregnancy, Family history and genetics in children with spina bifida. Zfur kinder chirugile. 1990; 45(2):72-77.

17. Carter $\mathrm{CO}$. Clues to the aetiology of neural tube malformation, Develop. Med. Child neurol. 1974; 16(supp-32): 3-15.

18. Hibbard ED, Smithells RW. Folic acid metabolism and human embryopathy. Lancet 1965; 1:1254.

19. MRC vitamin study research group. Prevention of neural tube defect. Results of medical research council. Vitamin study, Lancet, 1991; 338: 131-7

20. Centre for Disease control recommendation for use of folic acid to reduce the newborn of spina Bifida cases and other NTD. Jama. 1933; 1233: 163.

21. Viswell TE, Tuttle DJ, Northam RS, Simonds GR. Major congenital neurological malformations, A17 year survey. Ann Dis Child. 1990; 144(1): 61-67.

22. Lemire RJ. Neural tube defects. JAMA. 1988; 259: 558.

23 Bradshaw JR. Magnetic resonance imaging of CNS. Br. J Hosp Med. 1989;42:472-79.

24. Quinn MW. The doppler characteristics of hydrocephalus. MD, Thesis Trinity College, Dublin University. 1991.

25. Goh D. Minns RA, Pye SD. Transcranial Doppler Ultrasound as a non invasive monitoring cerebrohaemodynamic change in hydrocephalus. EUR J Paediatric Surg. 1991; 1: 14-17.

26. Reid A March, Banks RJ, Bateman DE al. Men intracranial pressure monitoring by a noninvasive audiological technique, a pilot study. J Neural Neurosurg, Psychiatry. 1989; 52:610-12.

27. Harrison MR. The fetus as a patient In: O'Neill JA, Row M, Grossfield JL, Fonkalsurd EW. 
Coran AG (eds), Paediatric Surgery. St. Luis Mosby; 1998; 38.

28. Bhatnagar V, Mitra DK, Upadhyaya P. Shunt infection in hydrocephalic children. Indian Pediatric. 1986; 12:255-57.

29. Sarguna P, Lakshmi V. Ventriculoperitoneal shunt infection. Indian J Med. Microbiology. 2006;24: 52-57.

30. Sharma Shilpa, Gupta DK, Shama SP, Gopal SC, Gangopadhyay AN. Pseudocyst formation following ventriculo-peritoneal shunt report of 2 case and review of literature. Journal of Indian association of Paediatric Surgeon. 2004; 9:87-91.
31. Zhou F, Che NG, Zhang J. Bowel perforation secondary to ventriculoperitoneal shunt; case report and clinical analysis. J Int Med Res. 2007; 35(6): 926-29.

32. Drake JM et al. Randomized trial of cerebrospinal fluid shunt valve design in Pediatric hydrocephalus. Neurosurgery. 1998; 43(2): 294303.

33. Kestle $\mathrm{J}$ et al. Long term follow up data from the shunt design trail. Pediatr Neuro Surg. 2000; 33(5): 230-36.

34. Roseau GL, MC Gullough DC, Joseph AL. Current prognosis in fetal ventriculomegaly. $J$ Neurosurgery. 1992; 77: 551-55. 